\title{
Do adverse events after manual therapy for back and/or neck pain have an impact on the chance to recover? A cohort study
}

\author{
Vesa Tabell', Ina M. Tarkka', Lena W. Holm² and Eva Skillgate ${ }^{2,3,4^{*}}$
}

\begin{abstract}
Background: Manual therapy is a commonly used treatment for patients with back and neck pain. Studies have shown that manual therapy-related adverse events are mainly short in duration and mild or moderate by their intensity, affecting up to $50 \%$ of the patients. If the presence of adverse events has an impact on the chance to recover from back/neck pain is poorly understood. The aim of this study was to investigate if mild or moderate adverse events after manual therapy has an impact on the chance to recover from back/neck pain in men and women.
\end{abstract}

Methods: A prospective cohort study of 771 patients with at least three treatment sessions in a randomized controlled trial performed in January 2010 - December 2013. Adverse events within $24 \mathrm{~h}$ after each treatment were measured with questionnaires and categorized as: no, mild or moderate, based on bothersomeness. Outcome measure was the perceived recovery at seven weeks and at three months follow-up. Odds Ratios (OR) and 95\% confidence intervals $(\mathrm{Cl})$ were calculated by Logistic regression to investigate the associations between the exposure and outcome, and to test and adjust for potential confounding.

Results: There were no statistically significant associations observed between the experience of mild or moderate adverse events and being recovered at the seven weeks follow-up. The only statistically significant association observed at the three months follow-up was for mild adverse events in men with an OR of 2.44, 95\% Cl: 1.24-4.80 in comparison to men with no adverse events.

Conclusion: This study indicates that mild adverse events after manual therapy may be related to a better chance to recover in men.

Trial registration: The study is based on data from a trial registered in Current Controlled Trials (ISRCTN92249294).

Keywords: Manual therapy, Adverse event, Low back pain, Neck pain, Recovery

\section{Background}

Patients suffering from disability related to low back pain (LBP) and neck pain (NP) have multiple evidencebased treatment options to choose from. Manual therapy (MT) seems to be a treatment option as effective as other modalities [1] and a cost-effective [2] treatment for certain musculoskeletal disorders. MT provided by naprapaths is well established in Sweden, Finland and

\footnotetext{
* Correspondence: eva.skillgate@ki.se

${ }^{2}$ Musculoskeletal \& Sports Injury Epidemiology Center, Institute of

Environmental Medicine, Karolinska Institutet, Box 210, SE-17177 Stockholm, Sweden

${ }^{3}$ Sophiahemmet University, Box 5605, SE-11485 Stockholm, Sweden Full list of author information is available at the end of the article
}

Norway and has been found to be an effective and cost-effective treatment [3-5].

Studies have shown that MT related adverse events (AE) are mainly short in duration and mild or moderate by their intensity, affecting up to $50 \%$ of the patients [6-8]. AE after spinal MT is reported as self-limiting, transient and located in the musculoskeletal system [9], usually including symptoms like musculoskeletal pain, tiredness, stiffness, dizziness, radiating discomfort, headache or nausea [10]. AE are reported more commonly by female patients [8-10].

It is generally accepted to measure $\mathrm{AE}$ in terms of severity, duration and nature $[8,11,12]$, and to classify 
$\mathrm{AE}$ as: mild, moderate or major/intense [11, 12]. Severe, irreversible $\mathrm{AE}$ are excluded from this classification. Most negative treatment-related $\mathrm{AE}$ is defined as pain and loss of function with impact on daily living or work $[12,13]$.

We have previously [8] shown that $\mathrm{AE}$ in patients with LBP and/or NP treated with naprapathic MT did not differ between MT with or without spinal manipulation. MT provided by naprapaths to treat pain and pain related disability in the musculoskeletal system, is a combination of manual techniques as spinal manipulation/ mobilization, stretching and massage. A systematic review of Carnes et al. [7] states that MT interventions produced more minor or moderate $\mathrm{AE}$ than general practitioner care, and equal number of $\mathrm{AE}$ as exercise therapy and less $\mathrm{AE}$ than drug therapy.

The role of AE for the positive effect of MT on LBP and NP has been studied by several researchers. Some studies have shown that AEs are not associated with recovery at three months follow-up for NP patients [14-16]. In contrary, others suggest that patient perception of $\mathrm{AE}$ being present may be of importance for a positive effect of MT [13]. The relationship between AE after MT for other conditions than NP, and if the potential association is modified by sex is still not well known. Our hypothesis is that $\mathrm{AE}$ after MT influence the prognosis in the short term, and that the occurence of AEs may be related to treatment induced cascade of neurophysiological responses [17] of the symptomatic tissues. This proprioceptive information including pain, [18] could be temporary and is induced by biomechanical changes in tissue loading. The potential influence of $\mathrm{AE}$ on the prognosis may be mediated through cultural and psychological characteristics e.g. expectations, and may differ between men and women.

The aim of this study was to study if mild or moderate $\mathrm{AE}$ after naprapathic MT have an impact on the chance to recover from back and/or neck pain in men and women.

\section{Methods}

This study is a secondary analysis of data from a randomized controlled trial (RCT) performed in January 2010 - December 2013, in Stockholm, Sweden. The study design is a prospective cohort study.

\section{Study population}

The study participants were selected among the included in the RCT called the Stockholm Manual Intervention Trial $(n=1057)$, with the main aim to compare the treatment effect and the risk of AEs between three different combinations of MT (spinal manipulation, mobilization, muscle stretching and massage) for patients seeking care for non-specific LBP and/or NP [8]. The study participants were patients (18-65 years old) seeking care for back and/or neck pain at the education clinic of the Scandinavian College of Naprapathic Manual Medicine in Stockholm, Sweden. Students in their seventh semester of the education delivered the treatments. Details of the trial including inclusion and exclusion criteria is presented elsewhere [8].

The study population in the present study was $771 \mathrm{pa}-$ tients. The inclusion criteria was to have had at least three treatment sessions and to have answered questionnaires about $\mathrm{AE}$ after the first three visits.

\section{Exposure}

AEs after MT, measured by paper questionnaires at all return visits at the clinic, were the exposure in this study. The questionnaire was given to the patients to fill in while waiting for the therapist and was handed in before the treatment session started. If the third treatment was the last session, a research assistant contacted the patient by telephone within a week to collect information regarding potential $\mathrm{AE}$ after the third treatment. Each of the $\mathrm{AE}$ questionnaire included eight questions concerning any $\mathrm{AE}$ present within $24 \mathrm{~h}$ after treatment. The introduction text on the questionnaire was; It happens that patients experience adverse events in connection with manual treatment therapy. Therefore, we wonder if you experienced any of the following events. Note that only symptoms within $24 \mathrm{~h}$ debut after the treatment session shall be reported. $\mathrm{AE}$ for the patients to report on were 1 . Tiredness, 2 . Soreness in muscles, 3. Stiffness, 4. Increased pain, 5. Nausea, 6. Headache, 7. Dizziness or 8. "Other". Bothersomeness from AE was measured with a numerical rating scale (NRS) from 0 to $10(0=$ had not bothered them at all, and $10=$ had bothered them in the worst possible way). If patient had not experienced $\mathrm{AE}$, bothersomeness was classified as 0 . We took the highest NRS-value for bothersomeness from the eight possible $\mathrm{AE}$ from each of the three return visits. These values were used to calculate the mean of bothersomeness of the three sessions for each patient. The exposure $\mathrm{AE}$ was then categorized into three levels based on the mean score, as no $(<1)$, mild $(1-3)$ or moderate/major $(\geq 4)$. A low proportion of patients $(3 \%)$ reached up to NRS $>7$ (major $\mathrm{AE}$ ), meaning that this group was to small to be analyzed separately.

Since many patients only needed three treatment sessions, we included only information from the AEquestionnaires delivered after the first three visits, so that all study participants had had the same number of treatments and thereby theoretically the same risk of $\mathrm{AE}$ after treatment.

\section{Outcome}

The outcome perceived recovery was self-reported measured with follow-up questionnaires at seven weeks and three months by the Global Perceived Recovery Question (6-point Likert scale). The question used was; 
"Which of the following statements best matches how you feel your symptoms in the neck/back have changed since you joined the study". The answering options were; a. "Feel no pain at all and no other symptoms from my neck or/and back", b. "Is considerably better", c. "Is slightly better", d. "No Improvement", e. "Is slightly worse", f. "Is considerably worse". Answers a and b were defined as recovered, and the rest as not recovered. Similar definitions and 6-point rating scale has been used in several studies $[8,15]$. The loss to follow-up of the outcome measured by questionnaires was $4 \%$ at seven weeks as well as at three months (Fig. 1).

\section{Potential confounders}

Potential confounding factors for the associations between the exposure and the outcome was identified through theoretical and empirical considerations and based on data available from the baseline questionnaire were the factors reported in Table 1.

\section{Statistical methods}

Descriptive statistics were used to summarize baseline characteristics. Several baseline variables were dichotomized and categorized for analyses. Duration of pain was dichotomized to acute/subacute ( $\leq 3$ months) and chronic ( $>3$ months). Pain intensity at baseline was measured with three numerical rating scales (NRS 0-10); pain right now, worst pain in the last four weeks and average pain of the last four weeks. Pain intensity was operationalized as the total mean value of the three scales. Pain related disability was operationalized and calculated in the same way but based on the following three questions about:1. how pain has hindered daily activities in the last four weeks, 2 . how much pain has affected social activities in the last four weeks and 3 . how much the pain has interfered with work during the last four weeks (NRS; $0=$ had no effect to function and $10=$ impossible to perform activities). General health categorization (1. Excellent, 2. Very good, 3. Good, 4. Fair and 5. Poor) was categorized as "good or better" (1, 2 and 3), "fair" (4) and "poor" (5).

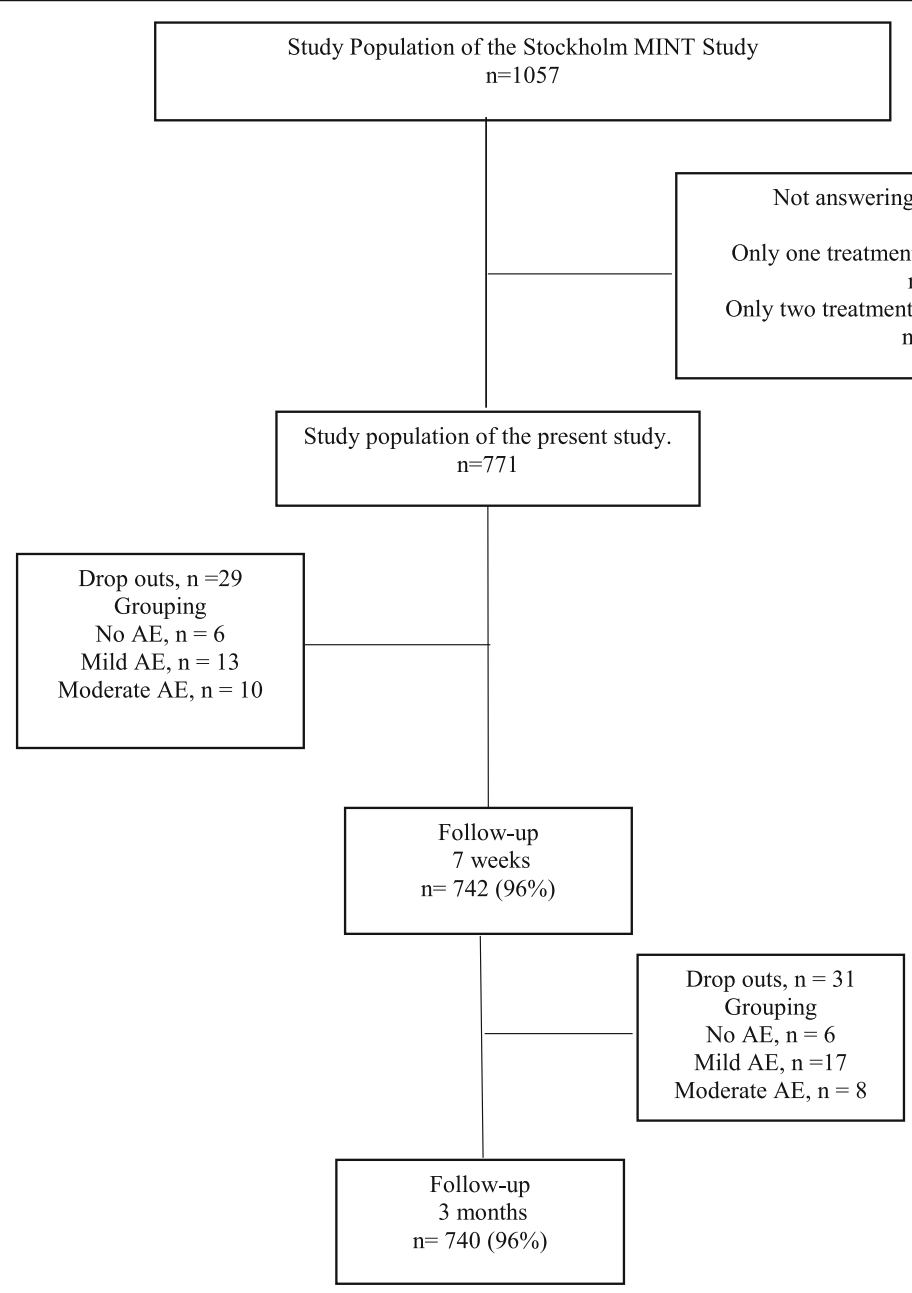

Fig. 1 Flowchart of the inclusion process 
Table 1 Baseline characteristics of study participants stratified by AE after first three visits, mean $(n=771)$

\begin{tabular}{|c|c|c|c|c|c|c|c|c|}
\hline \multirow[b]{2}{*}{ Characteristics } & \multicolumn{2}{|l|}{ All } & \multicolumn{2}{|c|}{$\begin{array}{l}\text { No AE } \\
\text { (NRS < 1) } \\
(n=182,24 \%)\end{array}$} & \multicolumn{2}{|c|}{$\begin{array}{l}\text { Mild AE } \\
\text { (NRS 1-3) } \\
(n=401,52 \%) \\
\end{array}$} & \multicolumn{2}{|c|}{$\begin{array}{l}\text { Moderate AE } \\
(N R S \geq 4) \\
(n=188,24 \%)\end{array}$} \\
\hline & No. & $\%$ & No. & $\%$ & No. & $\%$ & No. & $\%$ \\
\hline Mean age (SD) & $36(12)$ & & $36(12)$ & & $36(12)$ & & $36(12)$ & \\
\hline \multicolumn{9}{|l|}{ Gender } \\
\hline Women & 545 & 71 & 106 & 58 & 285 & 71 & 154 & 82 \\
\hline Men & 226 & 29 & 76 & 42 & 116 & 29 & 34 & 18 \\
\hline \multicolumn{9}{|l|}{ Painful area } \\
\hline Back & 255 & 33 & 79 & 43 & 123 & 31 & 53 & 28 \\
\hline Neck & 422 & 55 & 83 & 46 & 219 & 55 & 120 & 64 \\
\hline Back/Neck & 94 & 12 & 20 & 11 & 59 & 15 & 15 & 8 \\
\hline \multicolumn{9}{|l|}{ Duration of pain } \\
\hline Acute/subacute ( $\leq 3$ months) & 488 & 63 & 113 & 62 & 260 & 65 & 115 & 61 \\
\hline Chronic (> 3 months) & 283 & 37 & 69 & 32 & 141 & 35 & 73 & 39 \\
\hline Previous similar complaints & 599 & 78 & 137 & 75 & 312 & 78 & 150 & 80 \\
\hline Pain at baseline (SD) ${ }^{a}$ & 771 & & $5(2)$ & & $5(2)$ & & $6(2)$ & \\
\hline Disability at baseline $(\mathrm{SD})^{\mathrm{b}}$ & 771 & & $2(2)$ & & $2(2)$ & & $3(2)$ & \\
\hline Recovery expectations $(S D)^{c}$ & 771 & & $6(3)$ & & $6(3)$ & & $6(3)$ & \\
\hline \multicolumn{9}{|l|}{ General health } \\
\hline Good or better & 731 & 95 & 173 & 95 & 379 & 95 & 179 & 95 \\
\hline Fair & 40 & 5 & 9 & 5 & 22 & 6 & 8 & 4.5 \\
\hline Poor & 1 & $<1$ & 0 & 0 & 0 & 0 & 1 & 0.5 \\
\hline \multicolumn{9}{|l|}{ Education } \\
\hline Elementary school 1-9 y & 26 & 3 & 8 & 4 & 10 & 3 & 8 & 4 \\
\hline High school 10-12 y & 268 & 35 & 70 & 39 & 128 & 32 & 70 & 37 \\
\hline University $13-15$ y & 375 & 49 & 80 & 44 & 205 & 51 & 59 & 48 \\
\hline Higher academic education $\geq 16$ y & 102 & 13 & 24 & 13 & 58 & 15 & 20 & 11 \\
\hline Distress (SD) ${ }^{d}$ & & & $5(1)$ & & $5(1)$ & & $5(1)$ & \\
\hline Daily smoking & 105 & 14 & 18 & 10 & 56 & 14 & 31 & 17 \\
\hline \multicolumn{9}{|l|}{ RCT group } \\
\hline NMT & 244 & 32 & 62 & 34 & 121 & 30 & 61 & 32 \\
\hline NMT- no manipulation & 265 & 34 & 53 & 29 & 148 & 37 & 64 & 34 \\
\hline NMT- no stretching & 262 & 34 & 67 & 37 & 132 & 33 & 63 & 34 \\
\hline
\end{tabular}

Abbreviations: $A E$ adverse events, NRS, number rating scale, $S D$ standard deviation, $R C T$ randomized controlled trial, NMT Naprapathic manual therapy

${ }^{a}$ Average of three questions from $(0=$ no pain and $10=$ worse possible pain) how strong is the pain right now, intensity of the worst pain in the last four weeks and average of the last four weeks

${ }^{b}$ Average of three questions from $(0=$ had no effect on function and $10=$ impossible to perform activities) affection to function in the last four weeks, affection to social activities and affection to work

'Expectation of asymptomatic pain area in seven weeks $(0=$ not at all and $10=$ very likely)

${ }^{d}$ Have you felt gloomy and sad in the last four weeks $(1=$ all the time and $6=$ not at all)

To control the confounders statistically we used comparison of odds ratios calculated with logistic regression. Each potential confounder was tested by adding it to the model one at a time. If the adjusted model changed the point estimate with $10 \%$ or more, confounding was considered present and the factor was added to the final model. The test for confounding was performed for the total study sample as well as for men and women separately. The variable "treatment arm" of the original RCT was included in all the models no matter if it was a confounder or not.

Recovery expectations were defined as the patients self-rated likelihood of being symptom-free after seven weeks on an NRS $0-10(0=$ not at all likely and $10=$ very likely). The variable was used as a continuous variable in the analyses. Distress was defined by asking to which extent of 
time the patient felt gloomy and sad in the last four weeks, conducted on an NRS $1-6(1=$ all the time and $6=$ not at all), where all six categories were used in the analyses.

The sample size provided a power of $80 \%$ to find a relative risk of 1,3 for the outcome between the exposed and unexposed (epinet.se). Logistic regression modelling was used to determine odds ratios (OR) and 95\% confidence intervals (CI 95\%) for AE effect on perceived recovery. Statistical analysis was performed using IBM SPSS version 22 for Mac.

\section{Results}

Patient characteristics at baseline stratified by bothersomeness of AEs are shown in Table 1. The mean age of all was 36 years and $71 \%$ were women. Chronic pain was reported by $37 \%$ of the patients, the average pain was five (NRS 0-10) and the average of recovery expectations was six (NRS 0-10). General health was reported to be at least good by $95 \%$ of patients. AE were commonly reported; $81 \%$ of women and $66 \%$ of men reported some AE. No severe irreversible AE were reported.

The associations between $\mathrm{AE}$ and the chance to recover at seven weeks and three months follow-ups as well as the proportion of recovered patients in their respective groups are presented in Tables 2 and 3. There were no statistically significant associations observed between the experience of mild or moderate $\mathrm{AE}$ and being recovered at the seven weeks follow-up. The only statistically significant association observed at the three months follow-up was for mild AE in men with an OR of 2.44, 95\% CI: $1.24-4.80$ in comparison to men with no AE.

\section{Discussion}

The result of this secondary analysis of data from a large RCT suggests that mild AE after MT may improve the chance to be recovered three months after treatment in men seeking care for non-specific LBP and/or NP.

$\mathrm{AE}$ was not a prognostic factor when both genders were analyzed together. This is consistent with results in previous studies, where AE after MT were unrelated to outcome after three months [14-16]. Our results show that $\mathrm{AE}$ are common and that most cases are mild, which are in line with the results in previous studies $[6,7,9]$.

\section{Strengths and limitations}

Important strengths of this study were the large study population, the careful management of confounders and the high response rate. Potential confounders were identified through theoretical and empirical considerations and were available from the extensive baseline questionnaire. Recovery expectation is a well-known prognostic factor for NP and LBP and was a confounder adjusted for in most of the final analyses $[19,20]$. All study participants were patients seeking care for their complaints, thus they may have higher expectations for recovery than persons who do not seek care. However, this is not a source of bias since the study is etiological and recovery is compared between groups. A limitation is that there could be residual and unmeasured confounding bias of the results, caused by use of medication and from sport or work related traumas or overloads. Further patho-anatomical, neuro-physiological and cognitivebehavioral factors may effect recovery and thus potentially confound the associations.

We used the outcome perceived recovery that is considered to increase the external validity of the results [21] and that is a reliable assessment of current health status in people with musculoskeletal disorders [22]. Perceived recovery seems to correlate with changes in pain and disability scores during MT [23].

Even though data from long-term follow-ups is available in the original trial on which this study is based, we decided not to investigate the long-term effect of $\mathrm{AE}$ on recovery. This decision was made based on our hypothesis that it would be improbable that a short time reaction after a treatment would impact the result of the treatment in the long term.

The questionnaire used to measure the exposure $\mathrm{AE}$ and the patients rating of bothersomeness from $\mathrm{AE}$ has not been formally tested with regard to validity and reliability. This means that there may be a risk for non-differential misclassification of exposure, which may dilute the

Table 2 Associations between AE and recovery at seven weeks' follow-up presented as crude and adjusted Odds Ratio (OR) with 95\% confidence intervals (95\% Cl) $(n=742)$

\begin{tabular}{|c|c|c|c|c|c|c|c|c|}
\hline \multirow[b]{2}{*}{$\mathrm{AE}$} & \multicolumn{3}{|c|}{ All OR (95\% Cl) } & \multicolumn{3}{|c|}{ Men OR (95\% Cl) } & \multicolumn{2}{|c|}{ Women OR (95\% Cl) } \\
\hline & $\overline{N^{a}\left(n^{b}\right)}$ & Crude $^{c}$ & Adjusted $^{d}$ & $\overline{N^{a}\left(n^{b}\right)}$ & Crude $^{c}$ & Adjusted $^{d}$ & $\overline{N^{a}\left(n^{b}\right)}$ & Crude $^{c}$ \\
\hline No $($ NRS $<1)$ & $176(94)$ & 1.0 (ref.) & 1.0 (ref.) & $74(35)$ & 1.0 (ref.) & 1.0 (ref.) & $102(59)$ & 1.0 (ref.) \\
\hline Mild (NRS 1-3) & $388(212)$ & $1.05(0.74-1.50)$ & $1.14(0.79-1.64)$ & $111(61)$ & $1.36(0.76-2.46)$ & $1.46(0.78-2.69)$ & $277(151)$ & $0.88(0.56-1.39)$ \\
\hline Moderate/major (NRS $\geq 4)$ & $178(86)$ & $0.82(0.54-1.24)$ & $0.92(0.60-1.41)$ & $32(16)$ & $1.13(0.49-2.59)$ & $1.25(0.53-2.93)$ & $146(70)$ & $0.68(0.41-1.14)$ \\
\hline
\end{tabular}

Abbreviations: $\mathrm{AE}$, adverse events; $\mathrm{OR}$, Odds Ratio; $\mathrm{Cl}$, confidence interval; NRS, numeric rating scale(0-10)

${ }^{a}$ Number of patient in AE group

${ }^{\mathrm{b}}$ Number of recovered patient measured by perceived recovery in AE group

'Treatment arm included in analysis

${ }^{\mathrm{d}}$ Adjusted for treatment arm and recovery expectations 
Table 3 Associations between AEs and recovery at three months' follow-up presented as crude and adjusted Odds Ratios (OR) with 95\% confidence intervals (95\% Cl) $(n=740)$

\begin{tabular}{|c|c|c|c|c|c|c|c|c|c|}
\hline \multirow[b]{2}{*}{ Adverse events } & \multicolumn{3}{|c|}{ All OR (95\% Cl) } & \multicolumn{3}{|c|}{ Men OR (95\% Cl) } & \multicolumn{3}{|c|}{ Women OR $(95 \% \mathrm{Cl})$} \\
\hline & $\mathrm{N}^{\mathrm{a}}\left(\mathrm{n}^{\mathrm{b}}\right)$ & Crude $^{c}$ & Adjusted $^{d}$ & $N^{a}\left(n^{b}\right)$ & Crude $^{c}$ & Adjusted $^{e, f}$ & $\mathrm{~N}^{\mathrm{a}}\left(\mathrm{n}^{\mathrm{b}}\right)$ & Crude $^{c}$ & Adjusted $^{9}$ \\
\hline No $($ NRS $<1)$ & $176(93)$ & 1.0 (ref.) & 1.0 (ref.) & $73(34)$ & 1.0 (ref.) & 1.0 (ref.) & $103(59)$ & 1.0 (ref.) & 1.0 (ref.) \\
\hline Mild (NRS 1-3) & $384(210)$ & $1.08(0.75-1.54)$ & $1.19(0.82-1.72)$ & $112(67)$ & $1.72(0.95-1.12)$ & $2.44(1.24-4.80)$ & $272(143)$ & $0.83(0.53-1.91)$ & $0.84(0.55-1.40)$ \\
\hline $\begin{array}{l}\text { Moderate/major } \\
(\mathrm{NRS} \geq 4)\end{array}$ & $180(77)$ & $0.67(0.44-1.01)$ & $0.76(0.50-1.18)$ & $33(12)$ & $0.66(0.28-1.55)$ & $0.58(0.22-1.52)$ & $147(65)$ & $0.60(0.34-0.99)$ & $0.68(0.40-1.13)$ \\
\hline
\end{tabular}

Abbreviations: $\mathrm{AE}$, adverse events; OR, Odds Ratio; Cl, confidence interval; NRS, numeric rating scale (0-10)

${ }^{a}$ Number of patient in $\mathrm{AE}$ group

${ }^{\mathrm{b}}$ Number of recovered patient measured by perceived recovery in AE group

'Treatment arm included in analysis

${ }^{\mathrm{d}}$ Adjusted for treatment arm and recovery expectations

'Mild AE; Adjusted for treatment arm, recovery expectations and pain location

${ }^{f}$ Moderate AE; Adjusted for treatment arm and recovery expectations, distress, disability at baseline and pain duration

${ }^{9}$ Adjusted for treatment arm and pain at baseline (confounder for women regarding moderate AE)

associations studied. Since the intervention strategy was to give six treatments within six weeks, the absolute majority of the AE questionnaires were filled in within a week after the treatment session. This means that the risk of misclassification of exposure due to long recall periods is low. AE were categorized into nonexistent, mild or moderate, demonstrating the concept of Carnes et al. [11] with the same NRS values as a previous study [24]. Bothersome AEs (NRS > 7) were also considered by Carnes et al. [11]. However, only a very low proportion of patients (3\%) reached up to this level in our study sample thus the group was too small to study separately. These were included in the category "moderate" in the analyses. Further, choosing the highest value from each of the three questionnaires and calculating the mean of the three sessions does not take into account the potential cumulative effect of multiple AE in a single session. This may constitute a limitation in the classification of the exposure. Furthermore, studying the first three sessions combined do not determine if there is a specific effect on any or some of the individual sessions.

The result of this study adds to the knowledge that recovery from pain is a complex concept. Some tissues like intervertebral discs and ligaments, compared to muscles, responds slowly and perhaps incompletely to biomechanical chances [25]. After biomechanical unloading procedures achieved by MT and conditioning, the response could also be slow. Using MT and/or exercise produces forces interaction between motor and sensory control of the entire spine and related joints. This affects load-sensitive nerve endings located in muscle and tendons providing proprioceptive information including pain [18]. An alteration in loading of spine from "pain state" to "relief" needs readjustments in sensory-motor control and environment around sensory nerves [18]. These processes may have a role in the occurrence of AEs. Potential effect mechanisms may not only be biomechanical, but related to context and expectations. This may explain that we did find statistically significant associations in men but not in women.
Treatment related AE may be considered as a response to a biomechanical adaptation where nociceptors are stimulated through the unloading of painful tissues. Emphasis shall however be on recognizing unwanted severe changes so that they can be avoided. Since the presence of mild and moderate $\mathrm{AE}$ don't improve the chance to recover in women, AE should be avoided especially in women.

\section{Conclusion}

This study indicates that mild adverse events after manual therapy may be related to a better chance to recover in men.

\section{Abbreviations}

AE: Adverse Events; Cl: Confidence Interval; LBP: Low Back Pain; MT: Manual Therapy; NP: Neck Pain; NRS: Numerical Rating Scale; OR: Odds Ratio; RCT: Randomized Controlled Trial

\section{Acknowledgements}

We want to show our gratitude to students (DN39, DN40, DN41, DN42) and teachers at the Scandinavian College of Naprapathic Manual Medicine, patients who made this study possible and Anna Peterson for valuable contributions to the data collection.

\section{Funding}

This study was funded by the SNA.

\section{Availability of data and materials}

The datasets generated and/or analysed during the current study are not publicly available due to ongoing work with further publications but are available from the corresponding author on reasonable request.

\section{Authors' contribution}

ES and LWH designed the trial. All authors interpreted data. VT made the statistical analyses under supervision of ES. VT and ES wrote the first version of the manuscript. All authors (VT, IMT, LWH and ES) critically revised different versions of the manuscript, and all authors read the final version of the manuscript. ES is the corresponding author. All authors read and approved the final manuscript.

\section{Ethics approval and consent to participate}

This study is based on data from a randomized controlled trial, approved by the Regional Ethics Appeals Board in Stockholm, Karolinska Institutet,

Sweden (https://etikprovning.se/), 2009/1848-31/2. The trial was registered in Current Controlled Trials (ISRCTN92249294). All study participant gave their written informed concent to participate in the trial. 


\section{Consent for publication}

Not applicable.

\section{Competing interests}

The authors declare that there is no conflict of interest with any financial organization regarding the material discussed in this manuscript. The financial support for the submitted work was obtained from the Swedish Naprapathic Association (SNA). The funding bodies had no role in the design of the study, collection, analysis, or interpretation of data or in writing the manuscript. ES has a part time position at Karolinska Institutet partly financed by grants from the SNA. None of the authors have any competing interests.

\section{Publisher's Note}

Springer Nature remains neutral with regard to jurisdictional claims in published maps and institutional affiliations.

\section{Author details}

${ }^{1}$ Faculty of Sport and Health Sciences, University of Jyväskylä, Fl-40014 Jyväskylä, Finland. ${ }^{2}$ Musculoskeletal \& Sports Injury Epidemiology Center, Institute of Environmental Medicine, Karolinska Institutet, Box 210, SE-17177 Stockholm, Sweden. ${ }^{3}$ Sophiahemmet University, Box 5605, SE-11485 Stockholm, Sweden. ${ }^{4}$ Naprapathögskolan - Scandinavian College of Naprapathic Manual Medicine, Kräftriket 23A, SE-11419 Stockholm, Sweden.

\section{Received: 28 November 2018 Accepted: 28 March 2019}

\section{Published online: 12 June 2019}

\section{References}

1. Deyo RA. The role of spinal manipulation in the treatment of low Back pain JAMA. 2017;317(14):1418-9

2. Tsertsvadze A, Clar C, Court R, Clarke A, Mistry H, Sutcliffe P. Costeffectiveness of manual therapy for the Management of Musculoskeletal Conditions: a systematic review and narrative synthesis of evidence from randomized controlled trials. J Manip Physiol Ther. 2014;37(6):343-62.

3. Skillgate $E$, Vingard $E$, Alfredsson L. Naprapathic manual therapy or evidence-based care for back and neck pain: a randomized, controlled trial. Clin J Pain. 2007:23(5):431-9.

4. Skillgate $E$, Bohman T, Holm L, Vingård E, Alfredsson L. The long-term effects of naprapathic manual therapy on back and neck pain - results from a pragmatic randomized controlled trial. BMC Musculoskelet Disord. 2010;11:26.

5. Lilje S, Persson UB, Tangen S, Kasamoen S, Skillgate E. Costs and Utilities of Manual Therapy and Orthopedic Standard Care for low-prioritized orthopedic outpatients of working age: a cost consequence analysis. Clin J Pain. 2014;30(8):730-6.

6. Carlesso LC, Gross AR, Santaguida PL, Burnie S, Voth S, Sadi J. Adverse events associated with the use of cervical manipulation and mobilization for the treatment of neck pain in adults: a systematic review. Man Ther. 2010;15(5):434-44.

7. Carnes D, Mars TS, Mullinger B, Froud R, Underwood M. Adverse events and manual therapy: a systematic review. Man Ther. 2010b;15(4):355-63.

8. Paanalahti K, Holm LW, Nordin M, Asker M, Lyander J, Skillgate E. Adverse events after manual therapy among patients seeking care for neck and/or back pain: a randomized controlled trial. BMC Musculoskelet Disord. 2014b; 15(1):77.

9. Cagnie B, Vinck E, Beernaert A, Cambier D. How common are side effects of spinal manipulation and can these side effects be predicted? Man Ther. 2004;9(3):151-6.

10. Senstad O, Leboeuf-Yde C, Borchgrevink C. Frequency and characteristics of side effects of spinal manipulative therapy. Spine. 1997;22(4):435-40

11. Carnes $D$, Mullinger $B$, Underwood $M$. Defining adverse events in manual therapies: a modified Delphi consensus study. Man Ther. 2010a;15(1):2-6.

12. Carlesso LC, Cairney J, Dolovich L, Hoogenes J. Defining adverse events in manual therapy: an exploratory qualitative analysis of the patient perspective. Man Ther. 2011;16(5):440-6

13. Rajendran D, Bright P, Bettles S, Carnes D, Mullinger B. What puts the adverse in 'adverse events'? Patients' perceptions of post-treatment experiences in osteopathy - a qualitative study using focus groups. Man Ther. 2012;17(4):305-11.
14. Hurwitz EL, Morgenstern H, Vassilaki M, Chiang LM. Adverse reactions to chiropractic treatment and their effects on satisfaction and clinical outcomes among patients enrolled in the UCLA neck pain study. J Manip Physiol Ther. 2004:27(1):16-25.

15. Rubinstein S, Knol DL, LeboeufYde C, van Tulder MW. Benign adverse events following chiropractic Care for Neck Pain are Associated with Worse Short-term Outcomes but not worse outcomes at three months. Spine. 2008b;33(25):E950-6.

16. Trott CA, Ruiz Aguila ME, Leaver AM. The clinical significance of immediate symptom responses to manual therapy treatment for neck pain: observational secondary data analysis of a randomized trial. Man Ther. 2014; 19(6):549-54.

17. Bialosky JE, Bishop MD, Price DD, Robinson ME, George SZ. The mechanisms of manual therapy in the treatment of musculoskeletal pain: a comprehensive model. Man Ther. 2009:14(5):531-8.

18. Indahl A, Holm S. The sacroiliac joint; sensory-motor control and pain In: Vleeming A, Mooney V, Stoeckart R, editors. Movement, Stability \& Lumbopelvic Pain; integration of research and therapy: Churchill Livingstone; 2007. p. 104-11.

19. Ebrahim S, Malachowski C, Kamal el Din M, Mulla SM, Montoya L, Bance S, Busse JW. Measures of patients' expectations about recovery: a systematic review. J Occup Rehabil. 2015;25(1):240-55.

20. Palmlöf L, Holm LW, Alfredsson L, Skillgate E. Expectations of recovery - a prognostic factor in patients with neck pain undergoing manual therapy treatment. Eur J Pain. 2016;31 MAR 2016,n/a-n/a.

21. Fischer D, Stewart A, Bloch D, Lorig K, Laurent D, Holman H. Capturing the patient's view of change as a clinical outcome measure. JAMA. 1999;282(12): $1157-62$.

22. Kamper SJ, Ostelo RWJG, Knol DL, Maher CG, de Vet HCW, Hancock MJ. Global perceived effect scales provided reliable assessments of health transition in people with musculoskeletal disorders, but ratings are strongly influenced by current status. J Clin Epidemiol. 2010;63(7):760-6 e1.

23. O'Halloran B, Wright A, Cook CE. Original research. Criterion validation of the rate of recovery, a single alphanumeric measure, in patients with shoulder pain. Int J Sports Phys Ther. 2013;8(6):784-92.

24. Walker BF, Hebert JJ, Stomski NJ, Clarke BR, Bowden RSM, Losco B, French SD. Outcomes of usual chiropractic. The OUCH randomized controlled trial of adverse events. Spine. 2013;38(20):1723-9.

25. Adams M, Bogduk N, Burton K, Dolan P. The biomechanics of Back pain; 2006.
Ready to submit your research? Choose BMC and benefit from:

- fast, convenient online submission

- thorough peer review by experienced researchers in your field

- rapid publication on acceptance

- support for research data, including large and complex data types

- gold Open Access which fosters wider collaboration and increased citations

- maximum visibility for your research: over $100 \mathrm{M}$ website views per year

At $\mathrm{BMC}$, research is always in progress.

Learn more biomedcentral.com/submission 